\title{
Isolation, Identification and Detection of Staphylococcus aureus in Raw Chicken and Frozen Chicken Meat Products in Ludhiana, India by Standard Isolation Techniques and PCR Assay
}

\section{Nishchal Dutta ${ }^{*}$, H.S. Banga ${ }^{2}$, Sidhartha Deshmukh $^{2}$, Geeta Devi Leishangthem ${ }^{2}$ and Nittin Dev Singh ${ }^{2}$}

\author{
${ }^{1}$ Department of Veterinary Pathology, Khalsa College of Veterinary and Animal Sciences, \\ Amritsar-143002, Punjab, India \\ ${ }^{2}$ Department of Veterinary Pathology, College of Veterinary Science Guru Angad Dev \\ Veterinary and Animal Sciences University, Ludhiana-141004, Punjab, India
}

*Corresponding author

\section{Introduction}

The genus Staphylococcus is the most important genus present in the family Micrococcaceae having in its ambit thirty-two species. The members of this group are Gram- positive, spherical in shape, non-spore forming, non-motile with limited capsule formation (Harris et al., 2002). These bacteria grow well on most routine laboratory media at $37^{\circ} \mathrm{C}$. Colonies of the most Staphylococci spp. that grow on solid media are circular, 
smooth, opaque, raised, with white to pigments of different colors. Staphylococci are known to be facultative anaerobes, usually oxidase negative and catalase-positive. Coagulase production by staphylococci organism cause hemolysis of blood, but the pattern of hemolysis depends on both the source of the blood and the staphylococcal strain (Moraveji et al., 2014). The biochemical characters of different species of staphylococci have been well documented. Staphylococci are known to be ubiquitous in nature and are usually isolated from the outer body surfaces of mammals and birds besides also from blood, genitourinary tract, intestines, upper respiratory tract and other organs of the body. Staphylococci are the most common bacteria found in the environment where poultry are hatched, reared, and processed .They are also isolated from the skin and nares, feet and beak of healthy chickens. Staphylococcus aureus is one of the major foodborne pathogens in fresh and ready-to-eat products and recognized for causing various infections around the world. There are many foodborne diseases associated with Staphylococcus spp. where food handlers who have staphylococcal lesions of the skin, especially of the nasopharyngeal region and the hands, or who are carriers. Most of the contamination of chicken meat due to $S$. aureus was found due to cross-contamination, inadequate heat treatment of the foodstuff and improper storage resulted into outbreaks of food poisoning.

\section{Materials and Methods}

\section{Collection and processing of samples}

A total of 100 samples of poultry meat ( 80 raw chicken meat and 20 frozen meat) samples were collected from different retail shops in vicinity of Ludhiana. About 100 grams of meat samples were collected in dry, clean and sterile polythene bags and transported to the laboratory for microbiological analysis within one hour or refrigerated at $4^{\circ} \mathrm{C}$ till further analysis was carried out.

These samples were then processed no later than 48 hours after purchase. These samples were then swabbed with sterile cotton swabs and inoculated onto the Brain Heart Infusion broth (BHI) and then incubated overnight at $37^{\circ} \mathrm{C}$. On the next day, the swabs were streaked onto the different media plates like Brain Heart Infusion Agar (BHI), Mannitol Salt Agar (MSA) for isolation of Staphylococcus spp.

\section{Identification of bacterial isolates}

The bacterial colonies were isolated after incubation. These colonies were subjected to Gram's staining for identification and requisite biochemical tests were carried out to further confirm the presence of the pathogen. The final confirmation of the organism was done by using molecular technique like PCR assay.

\section{Biochemical characterization}

$S$. aureus suspected colonies were subjected to various biochemical tests like the Catalase test andStaphylococcus aureus identification kit (HIMEDIA) for Voges Proskauer, Alkaline phosphatase, ONPG, Urease, Arginine Utilisation and various carbohydrate utilization tests including Mannitol, Sucrose, Lactose, Arabinose, Raffinose, Trehalose, and Maltose utilization tests.

\section{Molecular characterization}

The DNA was extracted from suspected colonies and tissues using Himedia DNA extraction kits. The extracted DNA was subjected to PCR for the detection of bacterial DNA in the samples using published primers and probes. 


\section{Polymerase Chain Reaction (PCR)}

The DNA extracted was subjected to polymerase chain reaction using specific primers for Staphylococcus aureus. The $25 \mu \mathrm{l}$ reaction mixture for PCR was prepared that consisted of $13 \mu \mathrm{l}$ Mastermix (Promega), $1 \mu \mathrm{l}$ each of $20 \mathrm{pmol} / \mu \mathrm{l}$ Forward primer and Reverse primer, $5 \mu \mathrm{l}$ of DNA template and 5 $\mu 1$ of Nuclease free water. PCR was performed on $\mathrm{C} 1000$ touch thermocycler (Bio-Rad, USA) with the following conditions; an initial denaturation at $95^{\circ} \mathrm{C}$ for 5 minutes and later 35 cycles of denaturation at $94^{\circ} \mathrm{C}$ for 30 seconds, annealing at $60^{\circ} \mathrm{C}$ for 1 minute for $S$. aureus and extension at $72^{\circ} \mathrm{C}$ for 1 minute. The final extension followed at $72^{\circ} \mathrm{C}$ for 10 minutes. The PCR products were run on $1.5 \%$ agarose along with 100 bp DNA molecular weight marker (New England Biolabs, USA) at $5 \mathrm{~V} / \mathrm{cm}$ and visualized using a gel documentation system (AlphaImager, Alpha Innotech, USA).

\section{Results and Discussion}

A total of 100 meat samples (80 fresh raw samples and 20 frozen chicken meat products) were examined for the presence of $S$. aureus. The $S$. aureuswas isolated from a total of 31 samplesin fresh raw meat (28) and frozen chicken meat products (03)with a prevalence of $31 \%$ (Table no.1) which were Catalase positive and later confirmed by PCR detection at $118 \mathrm{bp}$ targeting $n u c$ - genesequence.

The samples following the standard protocol were streaked on Mannitol Salt Agar (MSA) (Chapman, 1945) for selective culture of $S$. aureus and yellow colonies with yellow zones in the media were obtained (Fig. 1). Gram's staining performed on suspected colonies showed the presence of Gram positive cocci organisms (Fig.2) discrete or in groups typical of S. aureus (Murdoch and Greenlees, 2004). The isolation results for $S$. aureus 31 out of
100 samples i.e. $31 \%$ are in congruenceto the observations of Banga (2018), GonclavesTenorio et al., (2018), Saliha et al., (2018), Shylaja et al., (2018), Wei-Wei et al., (2018), Reddy and Pusapukdepod (2019) and Zelalem et al., (2019) as 52\%, 39.9\%, 42\%, 21\%, $12.5 \%, 37.7 \%$ and $21 \%$, respectively from poultry meat and/or meat products.

Gundogan et al., (2005) undertook study on one hundred and fifty samples of raw chicken parts (giblets, carcass) for the presence of Staphylococcus aureus and found 80 samples i.e. $53.3 \%$ prevalence of S. aureus. Saikia and Joshi (2010) demonstrated the presence of microbial contaminants in retail chicken meat samples in North East India. They isolated different pathogenic microorganism viz. Escherichia coli (98\%), Staphylococcus aureus (20\%), Yersinia enterocolitica (23\%), Salmonella typhi $(20 \%)$ from chicken raw meat samples collected from the local meat markets. Ruban et al., (2012) reported prevalence of common food borne pathogens like Salmonella spp., Staphylococcus and E. coli in chicken meat obtained from markets in Bangalore under different processing conditions. The colonies picked from Mannitol Salt Agar (MSA) were subjected to Catalase test,which showed positive reactivity(Foster, 1996). Furthermore, biochemical test kit (Himedia) was used in the study for confirming the presence of S. aureus (Fig. 3) with the help of 12 tests for identification of $S$. aureusnamely MR test, Voges Proskauer, Citrate utilization, Indole, Glucuronidase, Nitrate reduction, ONPG, Lysine utilization tests and 4 different carbohydrates utilization tests. The results from kit confirmed the presence of $S$. aureus. All the samples were confirmed primarily with the help of its growth characteristics on selective media and then with the help of biochemical and immunological testing kits. Das and Mazumdar (2016) found the prevalence of staphylococcus from raw meat 
samples in Southern Assam. They collected 65 raw meat samples (chicken and goat) from various regions in and around Southern Assam and reported 17 samples (48.57\%) from chicken were positive for Staphylococci spp. based on screening of staphylococcal isolates was done on the basis of morphology,
Gram's stain, catalase, coagulase and mannitol fermentation tests according to standard protocols. In another study from retail outlets of Chennai, India the prevalence of different biotypes of $S$. aureus i.e. Clonal Complex 398 in chicken meat was carried out.

Table.1 Comparison of the detection of Staphylococcus aureus in meat samples using various techniques

\begin{tabular}{|c|c|c|c|c|}
\hline \multirow[t]{2}{*}{ Techniques } & \multicolumn{2}{|c|}{ Total fresh meat samples (80) } & \multicolumn{2}{|c|}{ Frozen Samples (20) } \\
\hline & $\begin{array}{c}\text { Staphylococcus } \\
\text { aureus }\end{array}$ & $\%$ & $\begin{array}{c}\text { Staphylococcus } \\
\text { aureus }\end{array}$ & $\%$ \\
\hline Isolation & 28 & 35 & 03 & 15 \\
\hline PCR & 28 & 35 & 03 & 15 \\
\hline Total & 28 & 35 & 03 & 15 \\
\hline Overall Total & \multicolumn{4}{|c|}{$(28+03)=31(31 \%)$} \\
\hline
\end{tabular}

Fig.1 Growth of S. aureus on Mannitol Salt Agar

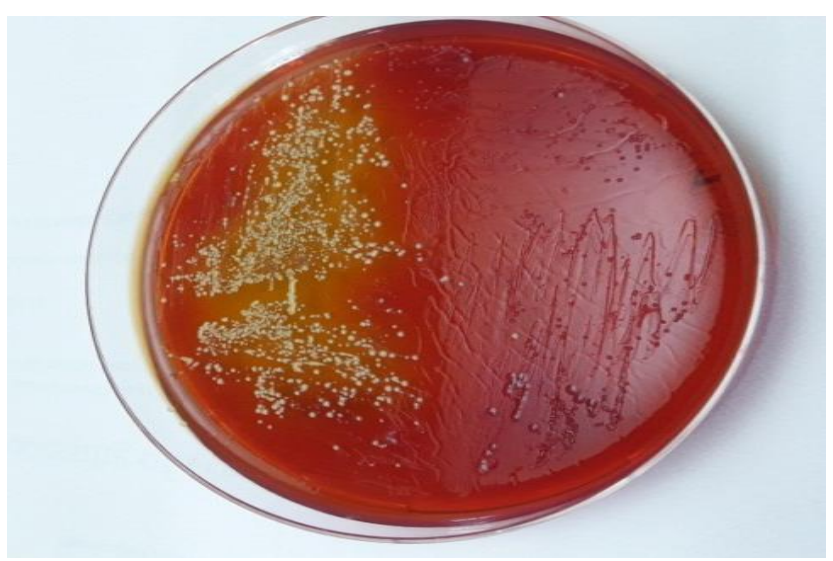

Fig.2 Microscopic view, note the typical grapes like clusters of S. aureus from culture. Gram's stain $\mathrm{x} 100$

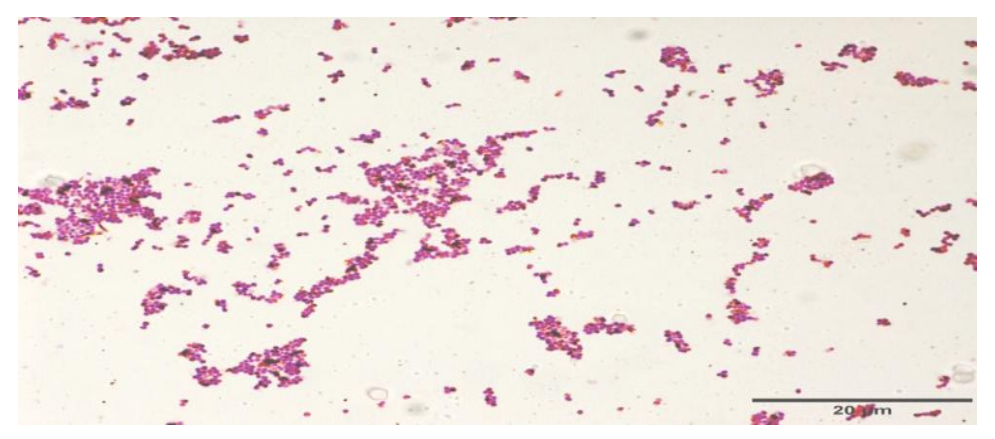


Fig.3 Biochemical test for S. aureus using kit by HiMedia showing positive reaction for $S$. aureus

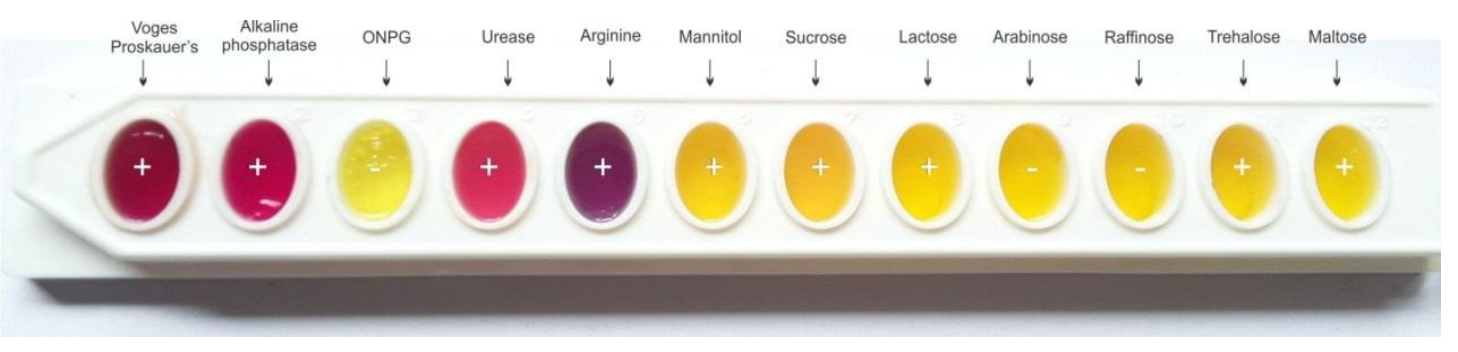

Fig.4 Molecular identification of $S$. aureus at 118 bp targeting nuc gene. M=100bp DNA ladder; L1 to L6= test samples showing distinct bands at $118 \mathrm{bp}$; PTC $=$ Positive template control; NTC= Negative template control

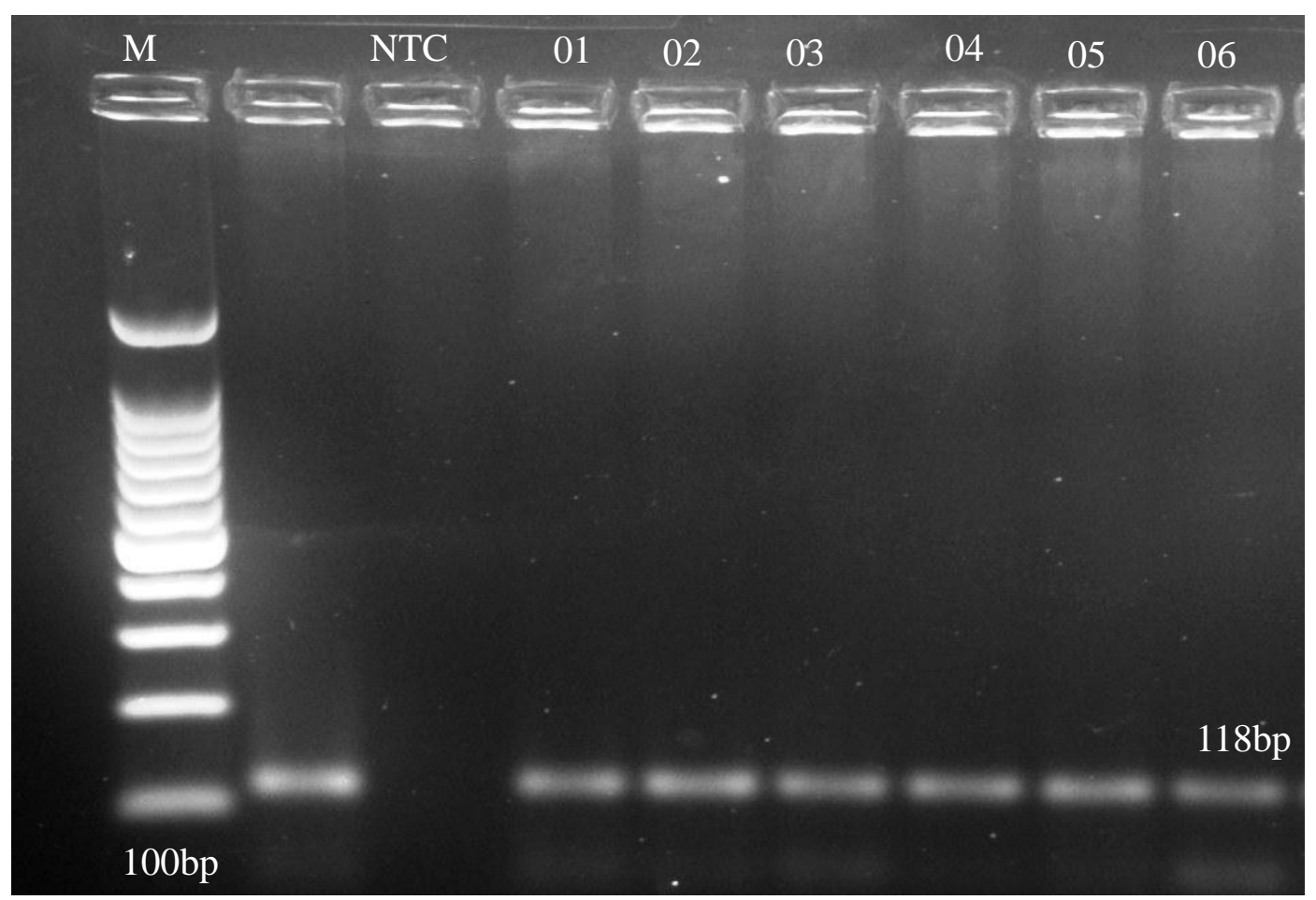

In the present study, standard PCR assay (Fig. 4) was employed to confirm the presence of Staphylococcus aureus by targeting nuc gene which amplified at target size of 118bp using published primers (Manga and Vyletelova 2013). Staphylococcus aureus was isolated from 28 fresh meat sample out of $80(35 \%)$ and 03 out of $20(15 \%)$ samples from the frozen meat with an overall prevalence of 29 (29\%) from the fresh and frozen meat samples. Other scientists have also used PCR for confirmation of $S$. aureus. Also in another study, Rusenova and Rusenov (2017) have used PCR for confirmation of isolated Staphylococcus aureus by amplification of DNA. Ruban et al., (2018) used PCR to confirm prevalence of $S$. aureus from 40 chicken isolates collected from retail outlets of Chennai, India, further suggesting its zoonotic potential. Shylaja et al., (2018) studied the incidence of Staphylococcus aureus in different meat and meat products 
samples. Out of 30 samples of chicken 17 $(56.66 \%)$, chicken nuggets $18(60.00 \%)$, sausages $16(53.33 \%)$, and burgers samples $17(56.66 \%)$, respectively were positive for Staphylococcus aureus by cultural method, whereas PCR assay revealed the incidence of Staphylococcus aureus to be $18(60.00 \%), 19$ $(63.33 \%), 17(56.66 \%)$ and $18(60.00 \%)$, respectively. The prevalence of Staphylococcus aureus by cultural method and PCR assay was determined in different meat and meat products samples. In a study in China it was observed that there were $12.5 \%$ of foodborne bacterial outbreaks caused by $S$. aureus, which showed the third most frequently occurring pathogen(Wei-Wei et al., 2018).

A total of 1105 samples collected from chicken meat processing plant and retail shops had 333 (30.13\%) prevalence of $S$. aureus. Staphylococcus aureus isolated from fecal $(28.88 \%)$, skin swabs $(40 \%)$, intestinal mucosa $(34.81 \%)$, and $45.18 \%$ environmental samples collected from processing plant had an overall prevalence of $37.77 \%$ (Reddy and Pusapukdepod 2019).

In conclusions, the present study revealed high proportion of Staphylococcus species $(31 \%)$ in raw chicken meat and frozen chicken meat products. Thirty one percent (31\%) isolation rate of Staphylococcus species from retail shops signals the existence of poor hygienic practices and consequently, its public health implication. Routine isolation, supplemented with molecular technique like PCR helped in better comprehension of meat pathogens.

\section{Acknowledgment}

We express our sincere thanks to the Science and Engineering Research Board (SERB), Ministry of Food Processing Industry, Government of India, for providing sufficient funds to carry out this research work in time bound manner.

\section{References}

Banga, J. 'Immunohistochemical localization of important meat borne pathogens in chicken'. M.V.Sc. Thesis, Guru Angad Dev Veterinary and Animal Sciences University, Ludhiana, India.2018.

Gundogan, N., Citak, S., Yucel, $\mathrm{N}$ and Devren, A. 2005. A note on the incidence and antibiotic resistance of Staphylococcus aureus isolated from meat and chicken samples. Meat Science, 69(4): 807-810.

Harris, L. G., Foster, S. J and Richards, R. G. 2002. An introduction to Staphylococcus aureus, and techniques for identifying and quantifying $S$. aureus adhesins in relation to adhesion to biomaterials: Review: European Cells and Materials, 4 pp. 39-60.

Luna, L.G. 1968. Manual of Histologic Staining Methods of the Armed Forces Institute of Pathology, $3^{\text {rd }}$ edn (McGrawHill, New York) 259.

Manga, I and Vyletelova, M. 2013.A new real-time PCR assay for rapid identification of the Staphylococcus aureus/MRSA strains .Acta Universitatis Agriculturae et Silviculturae Mendelianae Brunensis, 6: 1785-92.

Moraveji, Z., Tabatabaei, M., Shirzad, A. H and Khoshbakht, R. 2014. Characterization of hemolysins of Staphylococcus strains isolated from human and bovine, southern Iran. Iranian Journal of Veterinary Research, 15(4): 326-30.

Murdoch, D. R and Greenlees, R. L. 2004. Rapid identification of Staphylococcus aureus from BacT/ALERT blood culture bottles by direct Gram stain characteristics. Journal of Clinical 
Pathology, 57(2): 199-201.

Reddy, M.V.B and Pusapukdepod, J.2019.Prevalence of pathogenic organisms in meat samples of Ongkharak Nakhonnayok Thailand. International Journal of Pharmaceutical Sciences, 10(5): 233542.

Ruban, S. W., Babu, R. N., Porteen, K., Senthilkumar, T.M.A., Raja, P., Kumarasamy, P., Abraham, R. J. J and Rao, V. A. 2018. PCR based detection of S.aurues clonal complex 398 in Chicken and Mutton marketed in Chennai, India. Journal of Experimental Zoology India, 21(1): 217-20.

Ruban,W. S., Prabhu, N. K and Kumar, N. G. S. 2012.Prevalence of food borne pathogens in market samples of chicken meat in Bangalore. International Food Research Journal19(4): 1763-65.

Rusenova, N .V and Rusenov, A. G.2017.Detection of Staphylococcus aureus among coagulase positive staphylococci from animal origin based on conventional and molecular methods. Macedonian Veterinary Review40(1): 29-36.

Saikia, P and Joshi, S.R.2010.Retail market poultry meats of North-East India- a microbiological survey for pathogenic contaminants. Research Journal of Microbiology, 5: 36-43

Saliha, B. K., Mossadak, T. H., Hebib, A., Nacima, M and Zafer, C. 2018. Carriage methicillin-resistant Staphylococcus aureus in poultry and cattle in Northern Algeria. Veterinary Medicine International, 2018: 1-5.

Shylaja, M., Sanem, S.S. G., Samatha, K and Pradeep, C. H. 2018.Studies on the incidence of Staphylococcus aureus and its enterotoxins in different meat and meat products. The Pharma Innovation Journal7(4): 669-73.

Wei-Wei, L. I., Zhu, J. H., Zhen, S. Q., Liang, X. C., Jiang, Y. Y., Ning, L. I., et al., 2018. Analysis of foodborne disease outbreaks in China mainland in 2011. Chinese Journal of Food Hygiene. 30, 283-288.

Zelalem, A., Sisay, M., Vipham, J. L., Abegaz, K., Kebede, A and Terefe, Y. 2019. The prevalence and antibiotic resistance profile of bacterial isolates from meat and meat products in Ethiopia: A Systematic Review and Meta-Analysis. International Journal of Food Contamination 6(1): 1186.

\section{How to cite this article:}

Nishchal Dutta, H.S. Banga, Sidhartha Deshmukh, Geeta Devi Leishangthem and Nittin Dev Singh. 2020. Isolation, Identification and Detection of Staphylococcus aureus in Raw Chicken and Frozen Chicken Meat Products in Ludhiana, India by Standard Isolation Techniques and PCR Assay. Int.J.Curr.Microbiol.App.Sci. 9(07): 2095-2101.

doi: https://doi.org/10.20546/ijcmas.2020.907.243 